\title{
Relationship between Embryo Collection Results after Superovulation Treatment of Japanese Black Cows and Their Plasma $\beta$-carotene and Vitamin Concentrations
}

\author{
Fumio SEKIZAWA ${ }^{1,4)}$, Ken SAWAI ${ }^{2)}$, Minoru TANAKA ${ }^{3)}$ and Kiyoshi OKUDA ${ }^{4}$ \\ 1) Sekizawa Animal Clinic, Tochigi 329-2712, Japan \\ ${ }^{2)}$ Faculty of Agriculture, Iwate University, Iwate 020-8550, Japan \\ ${ }^{3)}$ Kenou Animal Hygiene Service Center, Tochigi 321-0905, Japan \\ 4) Graduate School of Natural Science and Technology, Okayama University, Okayama 700-8530, Japan
}

\begin{abstract}
The objective of this study was to investigate the relationship between the plasma concentrations of vitamin A (VA), vitamin E (VE) and $\beta$-carotene (BC) during embryo collection in Japanese Black cows that had undergone superovulation treatment and the embryo collection results. Following superovulation treatment in 116 Japanese Black cows, we collected 1317 embryos by nonsurgical means seven days after artificial insemination. The collected embryos were classified into transferable embryos, unfertilized oocytes and degenerated embryos. After embryo collection, we collected blood samples from the cows and measured the plasma concentrations of VA, VE and BC. The cows were then divided into 2 groups depending on the plasma concentration of VA ( $\mathrm{L}$ and $\mathrm{H}:<80 \mathrm{IU} / \mathrm{dl}$ and $\geq 80 \mathrm{IU} / \mathrm{dl}$ ), $\mathrm{VE}$ (L and $\mathrm{H}$ : $<150 \mu \mathrm{g} / \mathrm{dl}$ and $\geq 150 \mu \mathrm{g} / \mathrm{dl}$ ) and BC (L and H: $<150 \mu \mathrm{g} / \mathrm{dl}$ and $\geq 150 \mu \mathrm{g} / \mathrm{dl}$ ). As a result, the number of collected embryos in the $\mathrm{H}$ group of $\mathrm{VE}$ was significantly $(\mathrm{P}<0.01)$ higher than that in $\mathrm{L}$ groups. Furthermore, the number of transferable embryos was higher $(\mathrm{P}<0.05)$ in all VA, VE and $\mathrm{BC} \mathrm{H}$ groups than in the L groups. The $\mathrm{H}$ group for $\mathrm{BC}$ showed a high ratio of transferable embryos compared with the $\mathrm{L}$ group $(\mathrm{P}<0.05)$. Consequently, the present study suggests that the plasma $\mathrm{VE}$ and $\mathrm{BC}$ concentrations are positively correlated with the embryo collection results.

Key words: Embryo collection, Japanese Black cow, Superovulation treatment, Vitamin, $\beta$-carotene
\end{abstract}

(J. Reprod. Dev. 58: 377-379, 2012)

$\mathbf{T}$ efficiently produce calves through bovine embryo transfer, it is important to secure embryos for transplantation. Therefore, it is necessary to obtain embryos from cows that underwent superovulation treatment in an efficient manner. However, superovulated cows exhibit large individual differences in terms of the embryo collection results $[1,2]$. For example, it has been reported that when Holstein cows receive superovulation treatment, four or more normal embryos can be obtained from a significantly higher ratio of heifers with at least $90 \mathrm{mg} / \mathrm{dl}$ and multiparous cows with at least $130 \mathrm{mg} / \mathrm{dl}$ of serum total cholesterol than cows with lower levels of serum total cholesterol [3]. Furthermore, it has also been reported that in the case of crossbred multiparous cows, the number of embryos collected and the number of transferable embryos are significantly higher among cows with at least $140 \mathrm{mg} / \mathrm{dl}$ of serum total cholesterol [4]. These reports indicate the need for enhancing the lipid metabolism of donor cows in order to improve the embryo collection results [5]. On the other hand, another report demonstrated that superovulation treatment in crossbred heifers with low nutritional levels does not affect the number of embryos collected; however, it increases the developmental rate of blastocysts and

Received: May 30, 2011

Accepted: January 4, 2012

Published online in J-STAGE: February 1, 2012

(C)2012 by the Society for Reproduction and Development

Correspondence: K Sawai (e-mail: kensawai@iwate-u.ac.jp) the total cell number of blastocyst in in vitro embryo culture after embryo collection [6]. As stated above, various conflicting findings exist regarding the relationship between the blood constituents and nutritional levels of donor cows and their embryo collection results, thus leaving many details unclear.

Considering the fact that the concentrations of plasma vitamin A (VA) are low among cows with atretic follicles but high among cows with growing follicles, VA may regulate growth of dominant follicles [7]. Moreover, the concentrations of $\beta$-carotene (BC), vitamin $\mathrm{E}$ (VE) and VA in luteal tissue fluctuate in accordance with the growth stage of the corpus luteum; they are presumed to be involved in functional regulation of the structure [8]. In addition, it has been reported that the plasma $\mathrm{BC}$ concentrations are significantly lower among cows that developed ovarian cysts than among healthy cows [9]. As described above, it is evident that plasma vitamin and $\mathrm{BC}$ concentrations influence ovarian function in cows. However, the effects of plasma vitamin and $\mathrm{BC}$ concentrations on the embryo collection results after superovulation treatment have not been fully documented.

At present, determining whether or not to initiate superovulation treatment in donor cows is largely based on the size and hardness of the corpus luteum determined through rectal examination or ultrasonography, specifically, the morphological characteristics of the structure. However, this method lacks clarity in evaluation criteria and produces major differences in the embryo collection results after superovulation treatment. If one can predict the embryo 
Table 1. Effect of plasma concentration levels on embryo collection after superovulation treatment of Japanese black cows

\begin{tabular}{cccccc}
\hline & $\begin{array}{c}\text { Level of } \\
\text { plasma } \\
\text { concentration }\end{array}$ & $\begin{array}{c}\text { Number of } \\
\text { cows }\end{array}$ & $\begin{array}{c}\text { Number of collected } \\
\text { embryos } \\
\text { (mean } \pm \text { SEM) }\end{array}$ & $\begin{array}{c}\text { Number of transferable } \\
\text { embryos } \\
\text { (mean } \pm \text { SEM) }\end{array}$ & $\begin{array}{c}\text { Ratio of transferable } \\
\text { embryos } \\
\text { (mean\% } \% \text { SEM) }\end{array}$ \\
\hline VA & L & 67 & $10.4 \pm 1.2$ & $4.3 \pm 0.6^{\mathrm{a}}$ & $33.4 \pm 4.4$ \\
$\mathrm{HE}$ & $\mathrm{H}$ & 49 & $12.7 \pm 1.6$ & $7.1 \pm 1.1^{\mathrm{b}}$ & $45.8 \pm 5.1$ \\
& $\mathrm{~L}$ & 62 & $8.7 \pm 1.3^{\mathrm{c}}$ & $4.3 \pm 0.8^{\mathrm{a}}$ & $33.1 \pm 4.7$ \\
$\mathrm{BC}$ & $\mathrm{H}$ & 54 & $14.4 \pm 1.3^{\mathrm{d}}$ & $6.9 \pm 0.9^{\mathrm{b}}$ & $45.0 \pm 4.8$ \\
& $\mathrm{~L}$ & 100 & $11.3 \pm 1.1$ & $5.1 \pm 0.6^{\mathrm{a}}$ & $36.0 \pm 3.6^{\mathrm{a}}$ \\
\hline
\end{tabular}

VA, Vitamin A; VE, Vitamin E; BC, $\beta$-carotene. VA (L and H: $<80 \mathrm{IU} / \mathrm{dl}$ and $\geq 80 \mathrm{IU} / \mathrm{dl}), \mathrm{VE}(\mathrm{L}$ and $\mathrm{H}:<150 \mu \mathrm{g} / \mathrm{dl}$ and $\geq 150 \mu \mathrm{g} / \mathrm{dl}$ ) and $\mathrm{BC}(\mathrm{L}$ and $\mathrm{H}:<150 \mu \mathrm{g} / \mathrm{dl}$ and $\geq 150 \mu \mathrm{g} / \mathrm{dl})$. Different superscripts in the same column indicate significant differences ( ${ }^{\mathrm{a}}$ and ${ }^{\mathrm{b}}: \mathrm{P}<0.05 ;{ }^{\mathrm{c}}$ and ${ }^{\mathrm{d}}: \mathrm{P}<0.01$, respectively).

collection results of donor cows by measuring their blood vitamin and $\mathrm{BC}$ concentrations prior to superovulation treatment, it becomes possible to select cows that should be subjected to superovulation treatment, thereby enabling improvement of the quality of feed fed to donor cows by using plasma vitamin and $\mathrm{BC}$ concentrations as indices. Therefore, the aim of this study was to elucidate the relationship between the plasma VA, VE and BC concentrations and embryo collection results after superovulation treatment.

From a total of 116 cows, $11.4 \pm 1.0$ (mean \pm SEM) embryos were collected, of which $5.5 \pm 0.6$ were transferable embryos (normal embryo rate: $38.6 \pm 3.4 \%$ ). The plasma concentrations [mean $\pm \mathrm{SEM}$ (min.-max.)] of VA, VE and BC in the donor cows were $77.5 \pm 1.7$ (36.7-122.6) IU/dl, $158.0 \pm 6.2(24.5-317.0) \mu \mathrm{g} / \mathrm{dl}$ and $87.2 \pm 6.4$ (4.6-379.9) $\mu \mathrm{g} / \mathrm{dl}$, respectively. In this study, we divided the cows into 2 groups depending on the plasma concentrations of VA ( $\mathrm{L}$ and $\mathrm{H}:<80 \mathrm{IU} / \mathrm{dl}$ and $\geq 80 \mathrm{IU} / \mathrm{dl}$ ), VE (L and $\mathrm{H}:<150 \mu \mathrm{g} / \mathrm{dl}$ and $\geq 150 \mu \mathrm{g} / \mathrm{dl}$ ) and BC (L and $\mathrm{H}:<150 \mu \mathrm{g} / \mathrm{dl}$ and $\geq 150 \mu \mathrm{g} / \mathrm{dl}$ ). In regard to the VA and VE concentrations for dividing the groups, the average value of each plasma concentration was used. For the $\mathrm{BC}$ concentration, we referred to the average $\mathrm{BC}$ concentration of dairy cows that showed a significant delay in functional recovery of ovaries [10]. When then evaluated embryo collection results after superovulation treatment of each group (Table 1). As shown in Table 1, the number of collected embryos (14.4 \pm 1.3$)$ in the $\mathrm{H}$ group for VE was significantly $(\mathrm{P}<0.01)$ higher than that in the $\mathrm{L}$ groups $(8.7 \pm 1.3)$. The number of transferable embryos $(6.9-8.5)$ was higher $(\mathrm{P}<0.05)$ in the $\mathrm{H}$ groups for $\mathrm{VA}$, VE and $\mathrm{BC}$ than that in the L groups (4.3-5.1). The ratio of transferable embryos significantly $(\mathrm{P}<0.05)$ increased in the H group (55.2 \pm 9.5$)$ for the plasma BC concentration compared with the L group (36.0 \pm 3.6$)$. Our results suggest that the plasma vitamin and $\mathrm{BC}$ concentrations in the Japanese Black donor cows were positively correlated with the embryo collection results. In particular, the plasma VE and $\mathrm{BC}$ concentrations were correlated with two categories of embryo collection result.

Shaw et al. [11] reported that injection of VA at 1 million units on the same day as superovulation treatment increases the number of transferable embryos. Moreover, since the growth of follicles elevates the VA concentrations in follicular fluid, VA in follicular fluid is presumed to have an important correlation with follicular growth [12]. In addition, Sales et al. [13] reported that in relation to the embryo collection results of Holstein cows that underwent superovulation treatment, injection of $\mathrm{BC}(800 \mathrm{or} 1200 \mathrm{mg})$ and VE $(500$ or $750 \mathrm{mg}$ ) twice, on the day of implant administration of norgestomet and five days after implantation in donor cows, not only tended to increase the number of embryos collected but also significantly increased the number of transferable embryos. It has been postulated that $\mathrm{BC}$ contributes to follicular growth as the precursor substance of VA. Since a positive correlation was observed between the plasma vitamin and $\mathrm{BC}$ concentrations and the number of transferable embryos collected in this study, it is possible that such a plasma vitamin and $\mathrm{BC}$ contribute to follicular growth and the qualitative repletion of oocytes.

In the present study, plasma $\mathrm{VE}$ and $\mathrm{BC}$ concentrations were correlated with two categories of embryo collection result. BC has been known to function as an antioxidant in lipid phases by quenching singlet oxygen and scavenging the peroxyl radical [14]. It is possible that extracellular BC in the follicular fluid and intracellular BC incorporated into follicular cells and/or oocytes protects them from reactive oxygen species-mediated cytotoxity, thereby enhancing the developmental competence of oocytes. Retinol does not have the ability to quench singlet oxygen. Therefore, the uniqueness of $\mathrm{BC}$ in bovine fertility mentioned thus far may be related to this ability. Sales et al. [13] attributed this to the improvement of embryo quality due to the antioxidant effects of BC and VE. In the present study, a positive correlation between the plasma BC concentration and blood VE concentration was also observed $(\mathrm{r}=$ 0.57; data not shown). Therefore, a synergistic effect of plasma BC and VE may have caused them to function as antioxidants, thereby increasing the number of transferable embryos.

The relationship between endogenous plasma BC levels and embryo quality in superovulated Japanese Black cows was investigated by Goto et al. [15]. In that study, the animals were divided into 2 groups depending on the plasma concentration of $\mathrm{BC}(<200$ or $>200 \mu \mathrm{g} / \mathrm{dl}$ ) on the first day of superovulation treatment and on the day of embryo collection. The results showed that the numbers of transferable embryos in the $>200 \mu \mathrm{g} / \mathrm{dl}$ group were significantly larger than those in the corresponding $<200 \mu \mathrm{g} / \mathrm{d}$ l group. It was concluded that $>200 \mu \mathrm{g} / \mathrm{dl}$ of plasma BC is required for a good superovulation response in cattle. In the present study, a similar finding was obtained. It has been reported that when ovarian cysts are induced in Holstein cows by feeding them low BC feed, their 
plasma BC concentrations decrease significantly, whereas no significant difference is observed for VA [9]. Meanwhile, it has been revealed that when the plasma $\mathrm{BC}$ concentrations are maintained at high levels from $3.9 \mathrm{mg} / 1$ to $6.5 \mathrm{mg} / 1$ by feeding dry cows with excessive $\mathrm{BC}$, their conception rate decreased. Excessive intake of BC may have adverse effects on fertility [16].

In this study, we observed a positive correlation between the plasma BC and VE concentrations of Japanese Black cows and embryo collection results after superovulation treatment. Consequently, it is possible that plasma VE and $\mathrm{BC}$ concentrations are useful criteria for selection of donor cows. However, the optimum plasma vitamin and $\mathrm{BC}$ concentrations for donor cows in embryo collection using superovulation treatment are unknown, thus requiring further examinations. Nevertheless, enhancement of the quality of feed fed to donor cows, such as through optimal supply of vitamins and $\mathrm{BC}$, will lead to the improvement of the embryo collection results.

\section{Methods}

This experiment was performed by using a total of 116 Japanese Black cows reared on 41 farms in Tochigi Prefecture as donor cows from January to July 1994. As a superovulation treatment, we administered $28 \mathrm{mg}$ of a follicle-stimulating hormone (FSH; Antorin R10, Kawasaki Mitaka, Tokyo, Japan) twice daily for four days in a decreasing manner $(5,5,4,4,3,3,2$ and $2 \mathrm{mg})$. Then, $25 \mathrm{mg}$ of prostaglandin F2 $\alpha$ (PGF2 $\alpha$; Pronalgon F, Pfizer, Tokyo, Japan) was administered in two doses in the morning and evening (15 $\mathrm{mg}$ and $10 \mathrm{mg}$, respectively) to induce estrus on the third day after FSH administration. We performed artificial insemination (AI) $48 \mathrm{~h}$ after the second administration of PGF2 $\alpha$. Embryos were collected by nonsurgical means on the seventh day after $\mathrm{AI}$, and the collected embryos were classified into transferable embryos, unfertilized eggs and degenerated embryos according to the morphological indices using a stereomicroscope. The normal embryos were ranked as A (without morphological abnormality and all blastomere were normal), B (10-20\% of blastomeres were degenerate) or $\mathrm{C}$ (more than $30 \%$ of blastomeres were degenerate, but they still possessed a mass of cells that appeared viable) according to Kanagawa's classification [17]. Immediately after embryo collection, blood samples were collected from either the caudal vein or the caudal artery using a vacuum blood collection tube containing heparin, and the plasma was separated. The plasma obtained was stored at $-20 \mathrm{C}$. As a pretreatment, $0.5 \mathrm{ml}$ of the plasma was transferred to a brown centrifugal tube, in which $0.5 \mathrm{ml}$ of distilled water and $1 \mathrm{ml}$ of dibutylated hydroxytoluene-ethanol were mixed. Subsequently, after being stirred intensely with the addition of $5 \mathrm{ml}$ of $\mathrm{n}$-hexane, the mixture was centrifuged. Following centrifugation, $4 \mathrm{ml}$ of the n-hexane layer was transferred to another brown centrifugal tube, and the solvent was removed using an evaporator, leaving the sample, which was then quickly cooled to room temperature. The constituents obtained were dissolved in 300- $\mu 1$ of methanol:chloroform (7:3) solution. By injecting 20 $\mu l$ of the sample into a high-performance liquid chromatography apparatus (HPLC; LC-800 System, JASCO, Tokyo, Japan), VA, $\mathrm{VE}$ and $\mathrm{BC}$ were measured.

\section{Statistical analysis}

The percentage data for ratios of transferable embryos were subjected to an arcsine transformation. The number of collected embryos, number of transferable embryos and ratio of transferable embryos were analyzed by F-test for homogeneity of variance, followed by pair-wise comparisons using the Student's $t$-test. A P value less than 0.05 denoted a statistically significant difference.

\section{References}

1. Armstrong DT. Recent advances in superovulation of cattle. Theriogenology 1993; 39: 7-24. [CrossRef]

2. Hasler JF, McCauley AD, Schermerhorn EC, Foote RH. Superovulatory responses of Holstein cows. Theriogenology 1983; 19: 83-99. [CrossRef]

3. Kweon OK, Kanagawa H, Takahashi Y, Yamashina H, Seike N, Iwazumi Y, Aoyagi Y, Ono H. Factors affecting superovulation response in cattle. Jpn J Vet Sci 1986; 48: 495-503. [Medline] [CrossRef]

4. Balakrishnan M, Bhaskar BV, Chinnaiya GP, Arora VK, Ramu A, Sarma PA. Total cholesterol concentration in relation to superovuratory responses in crossbred cows. Theriogenology 1993; 40: 643-650. [Medline] [CrossRef]

5. Nakanishi Y, Kajisa O, Ezoe K, Goto K, Tasaki M, Ohta H, Inohae S, Tateyama S, Kawabata T, Ogawa K. Relationship between blood constituents and embryo quality in donor cattle. Anim Sci Technol 1991; 62: 546-551. (In Japanese).

6. Nolan R, O'Callaghan D, Duby RT, Lonergan P, Boland MP. The influence of short-term nutrient changes on follicle growth and embryo production following superovulation in beef heifers. Theriogenology 1998; 50: 1263-1274. [Medline] [CrossRef]

7. Schweigert FJ, Zucker H. Concentrations of vitamin A, $\beta$-carotene and vitamin $\mathrm{E}$ in individual bovine follicles of different quality. J Reprod Fertil 1988; 82: 575-579. [Medline] [CrossRef]

8. Schweigert FJ. Research note: changes in the concentration of $\beta$-carotene, $\alpha$-tocopherol and retinol in the bovine corpus luteum during the ovarian cycle. Arch Anim Nurt 2003; 57: 307-310.

9. Inaba T, Mezan M, Shimizu R, Nakao Y, Mori J. Plasma concentrations of $\beta$-carotene and vitamin A in cows with ovarian cyst. Jpn J Vet Sci 1986; 48: 1275 1278. [Medline] [CrossRef]

10. Kawashima C, Kida K, Schweigert FJ, Miyamoto A. Relationship between plasma $\beta$-carotene concentrations during the peripartum period and ovulation in the first follicular wave postpartum in dairy cows. Anim Reprod Sci 2009; 111: 105-111. [Medline] [CrossRef]

11. Shaw DW, Farin PW, Washburn SP, Britt JH. Effect of retinol palmitate on ovulation rate and embryo quality in superovulated cattle. Theriogenology 1995; 44: 51-58. [CrossRef]

12. Schweigert FJ, Lutterbach A, Rambeck WA, Zucker H. Vitamin A and $\beta$-carotene concentrations in bovine follicular fluid in relationship to follicle size. J Vet Med A 1986; 33: 360-364. [Medline] [CrossRef]

13. Sales JNS, Dias LMK, Viveiros ATM, Pereira MN, Souza JC. Embryo production and quality of Holstein heifers and cows supplemented with $\beta$-carotene and tocopherol. Anim Reprod Sci 2008; 106: 77-89. [Medline] [CrossRef]

14. Ikeda S, Kitagawa M, Imai H, Yamada M. The role of vitamin A for cytoplasmic maturation of bovine oocytes. J Reprod Dev 2005; 51: 23-35. [Medline] [CrossRef]

15. Goto K, Kajisa O, Ezoe K, Nakanishi Y, Ogawa K, Tasaki M, Ohta H, Inohae S, Tateyama S, Kawabata T. Relationship between plasma $\beta$-carotene concentration and embryo quality in superovulated Japanese Black cattle. Mem Fac Agr Kagoshima Univ 1989; 25: 113-117.

16. Folman Y, Ascarelli I, Kraus D, Barash H. Adverse effect of $\beta$-carotene in diet on fertility of dairy cows. J Dairy Sci 1987; 70: 357-366. [Medline] [CrossRef]

17. Kanagawa H. Bovine Embryo Tansfer. Second edition. Tokyo: Kindai Shuppan; 1988: 64-68 (In Japanese) 